DIRETOR DA FACULDADE DE CIÊNCIAS ECONÓMICAS:

Prof. Antônio Carlos Santos Rosa

VICE-DIRETOR: Prof. Nelson Rokembach

CHEFE DO DEPARTAMENTO DE CIENNCIAS ECONÓMICAS:

Prof. Renato Batista Masina

CONSELHO EDITORIAL: Prof. Pedro Cezar Dutra Fonseca (Presidente)

Prof. Achyles Barcelos da Costa

Prof. Carlos Augusto Crusius

Prof. Claudio Francisco Accurso

Prof. Edgar Augusto Lanzer

Prof. Ernani Hickmann

Prof. Nali de Jesus de Souza

Prof. Nuno Renan L. de Figueiredo Pinto

Profa Otilia Beatriz Kroeff Carrion

Prof. Roberto Camps Moraes

Profa Yeda Rorato Crusius

ANÁLISE ECONOMICA é uma publicação semestral da Faculdade de Ciências Econômicas da Universidade Federal do Rio Grande do Sul, visando divulgar estudos e pesquisas de seu corpo docente e discente na área de Economia. Aceitam-se, entretanto, artigos e resenhas bibliográficas de economistas e técnicos não vinculados à Instituição. As matérias assinadas são de responsabilidade exclusiva dos autores. É permitida a reprodução parcial para fins didáticos.

Toda a correspondência, material para publicação, assinaturas e permutas devem ser dirigidas a:

Prof. PEDRO CEZAR DUTRA FONSECA

Revista Anál ise Econômica

Avenida João Pessoa, $52-3^{\circ}$ andar

90.000 - Porto Alegre (RS) - Brasil 


\section{O MODELO DE DOIS HIATOS - O CASO BRASILEIRO RECENTE}

Flávio Soares Damico*

Este artigo tem por objetivo apresentar a formulação mais popularizada do modelo dos dois hiatos, procurando explorar suas conclusões para o caso brasileiro. Tenta-se ainda verificar possíveis trajetórias futuras através de um modelo preditivo simples.

\section{INTRODUÇĀO}

A experiência histórica de desenvolvimento das economias latinoamericanas reservou uma posição crítica aos problemas de Balanço de Pagamento e de restrição das possibilidades de crescimento econômico devido ao estrangulamento externo.

Com efeito, já década de 40, Raúl Prebisch, ao analisar as economias latino-americanas segundo o enforque estruturalista, diagnosticava o problema de escassez de divisas como óbice ao processo de substituição de importações. ${ }^{1}$ Posteriormente, nas décadas de 50 e 40, a expansão do comércio in. ternacional, o sucesso aparente das políticas de industrialização voltadas para o comércio exterior, à la ciclo do produto, além da fartura de capitais de rís-

Este artigo consiste na revisão do trabalho de diplomação em Economia apresentado pelo autor na Faculdade de Ciências Econômicas da UFRGS em novembro de 1982.

O autor agradece a seu Professor-Orientador - Nuno R. L. de Figueiredo Pinto pelas valiosas sugestões, críticas e icentivo. Desnecessário salientar que as opiniões aqui expressas e eventuais falhas são de responsabilidade exclusiva do autor.

Aluno do curso de Pós-Graduação em Economia do IEPE

1 Nesta tradição tem-se a interpretação da industrialização brasileira na década de $50 \mathrm{em}$ TAVARES, Maria da Conceição. Da substituição de importações ao capitalismo financeiro. Ed. Zahar.

\begin{tabular}{|l|l|l|l|c|}
\hline ANALISE ECONOMICA & ANO II & NO 3 & MAR/1984 & p.85-104 \\
\hline
\end{tabular}


co a juros baixos colocaram no ostracismo os resultados mais pessimistas dos estruturalistas. Contudo, ao ingressarmos num novo ciclo recessivo da economia mundial voltam à baila as conclusões do chamado modelo de dois hiatos.

Este modelo trata da problemática do equilíbrio externo representado pelo hiato de recurso (balança comercial mais serviços de fatores produtivos) frente ao equilíbrio interno dado pelo hiato do produto. O quadro geral de análise é complementado pela hipótese de estarmos tratando com economias semi-industrializadas, cuja atividade econômica normal depende do aporte de bens não-competitivos com a produção interna.

Discute-se neste artigo a especificação do modelo apresentada por Edmar Bacha em três artigos diferentes, procurando sintetizar as característi. cas mais importantes e, na medida do possivel, apresentar alguma crítica. ${ }^{2}$

\section{2 - O MODELO DOS DOIS HIATOS}

Trata-se de um modelo dinâmico de crescimento baseado na noção de acelerador de Harrod-Domar que permite prever uma taxa de crescimento equilibrado do tipo "fio da navalha". A versão do modelo que apresentaremos foi criado na tentativa de superação de visão clássica do financiamento externo como mera edição à poupança interna tomada como necessariamente insuficiente.

As conseqüências normativas advindas da concepção clássica de estrangulamento do crescimento por insuficiência de poupança interna são claras:

- aumento da propensão a poupar, via concentração de renda ou pela potencialização de um mercado de capitais;

- elevação da relação produto-capital.

A visão clássica parte da idéia de que a poupança gera o investimento, contudo a visão que adotaremos, baseada no princípio da Demanda Efetiva, considera que o investimento gera sua própria poupança. Desta maneira, se o Estado adota uma política monetária passiva, o nível de atividade é determi-

(2) Edmar Bacha apresenta versões simplificadas dos desenvolvimentos teóricos do modelo de dois hiatos precursores foram Chenery e McKinnon. Procurou-se neste artigo apresentar uma visão compacta do modelo, salientando as principais conclusões

(3) A escolha deste suporte teórico é referendada pela experiência histórica brasileira, na qual o crescimento atingido nos últimos trinta anos fez-se praticamente sem grandes mudanças nos coeficientes de poupança. 
nado pelo ânimo dos capitalistas em investir e pelo montante de gastos autônomos, incluído aí o déficit fiscal.

Considera-se em primeiro lugar a restrição-poupança. A economia em questão é aberta e sem governo. O equilíbrio interno é dado pela igualdade entre investimento e poupança mais o déficit da Balança Comercial. Assim, sejam: $\mathrm{I}=$ investimento, $\mathrm{S}=$ poupança, $\mathrm{M}=$ importações e $\mathrm{X}=$ exportações, tem-se:

$$
\mathrm{I}=\mathrm{S}+(\mathrm{M}-\mathrm{X})
$$

A poupança é função do nível de renda, ou seja, $S=s Y$ onde $s=$ propensão a poupar. Pode-se sofisticar mais este modelo incluindo-se a poupança do governo e dos assalariados. A poupança do setor governo constituise numa adição à poupança privada, enquanto que a poupança dos assalariados constitui-se num vazamento dos lucros dos capitalistas. Estas considerações acabam trazendo em consideração a distribuição de renda.

Assim levando em conta as afirmativas acima, deve-se tomar uma especificação mais completa da função poupança, englobando o nível de renda, sua distribuição, bem como a inflação. A contribuição de inflação para o aumento da poupança advém da piora causada na distribuição de renda salarial perfeita no Brasil.

Outro autor, McKinnon 4 , considera que a propensão a poupar deve ser entendida como máxima apenas no caso de não haver ponto de estrangulamento na canalização de poupanças ao aparato produtivo da economia. Tal hipótese sustenta-se no fato de que, em muitos países subdesenvolvidos, o aparelho de intermediação financeira é ainda muito incipiente para captar integralmente o excedente que termina por disipar-se. Evidentemente, tal dificuldade não é familiar ao Brasil, porém as considerações sobre o problema do financiamento são essenciais para o desenvolvimento das conclusões deste trabalho.

Voltando ao modelo pode-se substituir $(\mathrm{M}-\mathrm{X}$ ) por $\mathrm{F}$, que representa o montante de financiamento externo necessário para cobrir o déficit da Balança Comercial. Toma-se ainda $f=F / Y^{k}$ que representa a entrada de capital por unidade de produto potencial. $\mathrm{Y} / \mathrm{Yk}^{\mathrm{k}}$

Considera-se ainda o nível de utilização da capacidade instalada $\mathbf{u}=$

(4) McKINNON, R. "Restrições de divisas no desenvolvimento econômico e alocação eficiente da ajuda externa "in SAVASINI, J. \& MALAN, P. (org.) Economia Internacional. Ed. Saraiva. 
Dividindo a expressão (1) por $Y^{k}$ e tomando em conta as definições de $s$, u e $f$, chega-se expressão da taxa de investimento $I / Y^{k}$ para a economia: $1 / Y^{k}=f+s u$

Vendo a expressão pela óptica do crescimento do produto potencial, tem-se que a relação entre este e o estoque de capital é dada por a, que representa a relação produto-capital. Em termos de expressão: $Y^{k}=a K$. Introduz-se aqui uma restrição - o estoque de capital não se deprecia, portanto, o investimento líquido é igual ao investimento bruto. Logo, o crescimento do produto potencial é dado por:

$A Y^{k}=$ al

Dividindo-se (3) por $\mathrm{Y}^{\mathrm{k}}$ tam-se:

$\triangle Y^{k} / Y^{k}=a l / Y^{k}$

Finalmente, substituindo (2) em (4), tem-se:

$\triangle Y^{k} / Y^{k}=$ asu + af

Tomando $u=1$, ou seja, produto efetivo igual ao produto potencial, e a e s como constantes no curto prazo, teremos a taxa de crescimento como função da entrada de capitais. Por outro lado, quando a entrada de capitais é igual a zeo, a taxa garantida de crescimento é igual a as, resultado que reproduz o desenvolvimento de Harrod-Domar para economia fechadas.

Contudo, a especificação clássica da restrição poupança acima desenvolvida, não capta aspectos estruturais essenciais para economias semi-industrializadas. Assim, estidaremos o déficit estrutural, assumindo as seguintes hipóteses:

- exportações como função do desenvolvimento do potencial produtivo da economia;

- importaç̃ões de bens intermediários dependentes do nível de renda;

- importações de bens de capital como proporção dos investimentos.

Desta forma, pode-se chegar a resultados radicalmente diferentes dos resultados clássicos.

Voltando ao modelo tem-se o financiamento do déficit da Balança Comercial:

$$
F=M-X
$$

A função de importações contitui-se apenas de bens intermediários (i) e bens capital ( $k$ ) não-competitivos com a produção interna, uma vez que um processo prévio de substituição de importações internalizou a produção de bens de consumo final (duráveis e não-duráveis) e parte das necessidades do demais bens. Assim, as importações de bens intermediários são dadas por:

$$
M_{i}=m_{i} Y
$$


As importações de bens de capital, por sua vez, tem a seguinte expressão:

$M_{k}=m_{k} l$

Os coeficientes $m_{k}$ e $m_{i}$, propensões a importar, devem ser entendidos como coeficientes técnicos da matriz insumo-produto, desde que suponhamos preços relativos constantes, ou seja ausência deterioração dos termos de intercâmbio.

A função de exportações, por outro lado, é:

$\mathrm{X}=\mathrm{x} \mathrm{YK}^{\mathrm{K}}$

Esta forma de especificação indica que quanto mais desenvolvida e diferenciada for uma economia, tanto maior será o seu potencial de exportação. No caso brasileiro, poder-se-ia sofisticar esta função uma vez que as exportação de alguns setores, como os bens manifaturados simples, tem o caráter de escoamento de excedentes. Cabe ressaltar que é recorrente na literatura econômica brasileira a constatação de capacidade ociosa no setor de benssalário.

A utilização das exportações como instrumento de política econômica está condicionanda à posição ocupada pelo país no comércio internacional, que pode se dar segundo pontos de vista discrepantes:

- visão de programação;

- visão estruturalista.

A visão de programação toma as exportações como instrumento de política econômica do governo na procu ra de um nível ótimo para as necessidades de divisas do país. Esta visão sustenta-se no caso de um "país pequeno" no comércio internacional, ou seja, um país cujas exportações são marginais em relação ao montante destes comercializado internacionalmente.

Por sua vez, a visão estrutiralista adota a idéia de que exista excesso de oferta de determinadas mercadorias no comércio internacional de modo que qualquer tentativa de forçar um aumento no quantum exportado esbarra na capacidade de absorção do mercado. Uma das conseqüências possíveis desta tentativa de expansão seria a determinação dos termos de in tercâmbio.

Retornando ao modelo, e substituindo (6), (7) e (8) em (1.1) tem-se:

$F=m_{i} Y+m_{k} l-x Y^{k}$

Colocando (9) em função de $m_{k} l$ :

$m_{k} l=x Y^{k}-m_{i} Y+F$ 
Manipulando algebricamente, dividindo (9.1) por $Y^{k}$, obtem-se a ta$x a$ de investimento da economia que multiplicada pela relação produto-capital permite isolar a taxa de crescimento:

$$
\Delta Y^{k} / Y^{k}=a / m_{k}\left(x-m_{i} u\right)+a / m_{k} f
$$

Expressando a taxa de crescimento em função da entrada de capitais como no desenvolvimento anterior, verifica-se que se $f=0$, a taxa de crescimento se verá limitada pelos requisitos estruturais $a / m_{k}\left(x-m_{i} u\right)$ inferior a taxa de crescimento garantida pela restrição-poupança, conforme o gráfico 1.

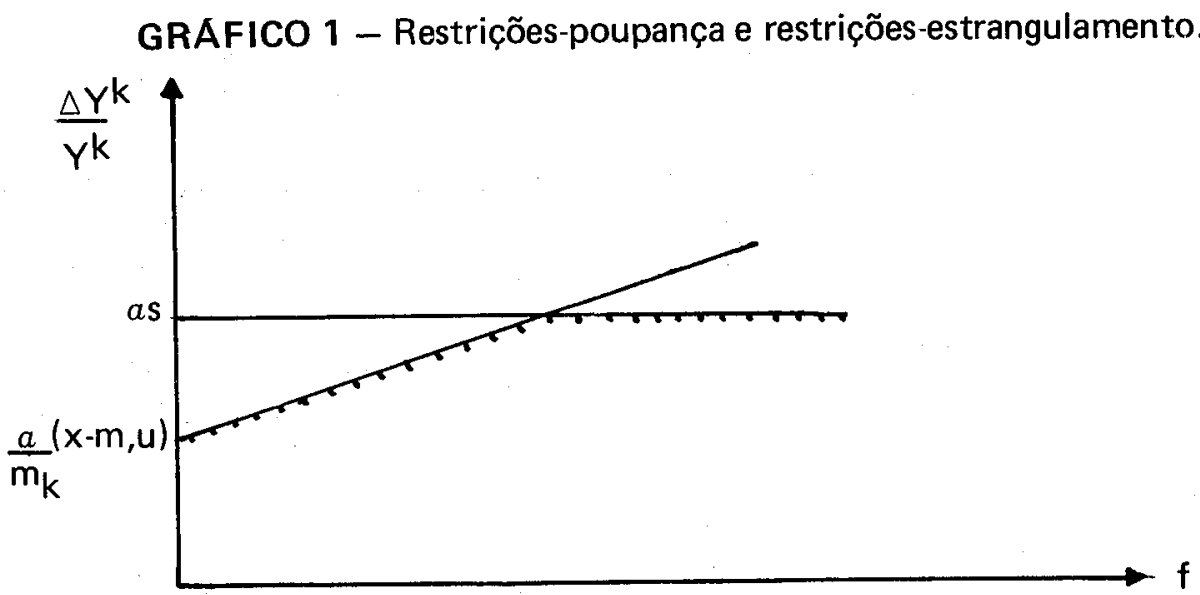

Contudo a partir da chegada de capitais externos a taxa de crescimento, no caso da restrição-estrangulamento, será superior à restrição-poupança. Tal se deve ao fato das despesas em bens de capital externos representarem apenas uma fração da formação de capital doméstica, de forma que os efeitos multiplicadores propagam:se com maior velocidade. Este resultado é conhecido na literatura como Teorema de Chenery, o qual indica ser a produtividade dos capitais externos maior na restrição-estrangulamento do que na restrição-poupança. Assim, o Teorema de Chenery é válido enquanto $e / m_{k}\left(x-m_{i} u\right), a / m_{k} f<a(s+f)$. A partir do momento em que ambos os termos se igualam, passa a valer a restrição-poupança.

Reconhece-se que a restrição-estrangulamento está bastante mais próxima da realidade latino-americana e brasileira. Os termos que indicam o limite de crescimento sem aporte de capitais $-m_{k}, m_{j}, x$ - serão as variáveischave sobre as quais a política econômica deverá atuar. Além disso, confirma-se um resultado clássico do pensamento econômico latino-americano - 
e importância do comportamento dos termos de intercâmbio - pois uma mudança nos preços relativos de importações e exportações pode representar uma restrição à taxa de crescimento.

Manipulando (9.2) também verifica-se que há um trade-off entre equilíbrio interno e externo, retirando graus de liberdade da política econômica.

Outro problema que merece atenção, ao analisar-se a possibilidade de manutenção de uma taxa de crescimento mais elevada que aquela permitida pelas características estruturais da economia via aporte de capitais externos, diz respei to à possibilidade de ressarcimento destes créditos. Para que o aporte destes fundos seja diminuído, é necessário um aumento da propensão a poupar da economia. Alternativamente, ter-se-ia o mesmo efeito via aumento da propensão a exportar ou via aumento da poupança de divisas pela queda da propensão a importar. Salienta-se que a propensão a exportar é um parâmetro de controle mais difícil, uma vez que relaciona-se com outra variáveis tais como grau de protencionismo dos importadores e diferentes elasticidades da demanda. Além disso, no atual momento recessivo da economia mundial, a maioria dos países adotam políticas do tipo "beggar my neighbour" (que empobreça meu vizinho), procurando salvaguardar o nível de emprego interno.

Pelo exposto acima tem se patenteado a necessidade de geração de meios de pagamento internacionais para permitr que a rolagem dos créditos seja feita em termos racionais. Uma das soluções que, aparentemente, é bas tante atrativa consiste na continuação do processo de substituição de importações, desta vez voltado para o setor de bens de capital e para alterações na matriz energética. Por outro lado, um processo como este pode requerer um percentual maior de divisas que aquele requerido pela atual estrutura, estando pois em contradição com as metas a serem alcançadas.

Na seção seguinte analisa-se o período recente da economia brasileira, a política econômica e as alternativas para os dilemas rapidamente expostos nesta seção.

\section{3 - A ECONOMIA BRASILEIRA NO PERIODO RECENTE}

\subsection{O Quadro Geral}

Nesta seção faz-se uma pequena resenha dos fatos estilizados da economia brasileira no periodo recente. A ênfase principal será dada aos fatos 
relativos ao equilíbrio interno e externo, bem como ao seu inter-relacionamento.

O entendimento da realidade econômica brasileíra atual torna-se-ia incompleto caso a análise não se detivesse no Governo Kubitschek, mais precisamente no Plano de Metas, onde se localiza a gestação do modo de acu. mulação centrado na indútria de bens de consumo durável, que ainda é predominante no Brasil.

A viabilização desta estratégia foi possível graças a entrada maciça de investimentos diretos externos que montaram toda a infra-estrutura industrial necessária. Este aporte de capitais foi obtido graças a liberal Instrução 113 da SUMOC. Na verdade o financiamento externo direto foi a alternativa encontrada para a superação do estrangulamento externo relativo (capacidade de importar crescia a taxas inferiores às do PIB) provocada pela deterioração dos termos de intercâmbio.

$\mathrm{Na}$ medida em que se tem as restrições externas superadas, aumentou a taxa de crescimento com a conseqüente aproximação do produto efetivo do potencial, conforme Quadro 1 no Apêndice.

A crise do período $62 / 67$ deve ter sua gênese buscada também no Plano de Metas. Tal sucedeu-se na medida em que o pacote de investimentos externos esgotou-se pela própria diminuição de oportu nidades de investimento pela estreiteza de mercado. 5 Presencia-se, portanto, uma queda no nível de atividades, ao mesmo tempo em que o setor externo mantém-se estável com poucas flutuações. O Quadro 2 do Apêndice ilustra o comportamento do setor externo no período 60/80.

O período 64/67 traz série de reordenamentos na economia - reformas administrativa, financeira, bancária e tributária, contribuindo todas para a retomada da expansão no período subseqüente ao criarem um aparato institucional mais adequado ao novo padrão de acumulação inaugurado no Plano de Metas. Cabe destacar, com maior ênfase, as reformas tributária e cambial como essenciais ao desempenho futuro do setor exportador.

A concentração tributária em mãos da União permitiu-the agir com maior liberdade no trato de isenções e imunidade para produtos de exportação, bem como facilitou a concessão de subsídios. A reforma combial, por sua vez, ao instituir as minidescalorizações procurava manter a competitividade dos produtos brasileiros, tendo em vista as inflações interna e internacional, além de evitar surtos especulativos com divisas.

(5) Conforme TAVARES, op. cit. 
Conforme o exposto, vê-se ser recorrente aos responsáveis pela política econômica a necessidade de promoção de exportações como forma de romper o estrangulamento externo. Com efeito, no ano de 1968 começava-se a alcançar resultados animadores (conforme os Quadros $1 \mathrm{e} 2$ ).

A conjuntura acima descrita, aliada a melhoria dos termos de intercâmbio e o aumento da liquidez internacional 6 permitiram a retomada da expansão do nível de renda graças às reservas de capacidade ociosa e a uma política de crédito passiva. $\mathrm{O}$ auge $68 / 74$ trouxe consigo uma necessidade crescente de importações de bens intermediários e de capital, conforme Quadro 3 do Apêndice.

Em 73/74 tem-se o choque do petróleo que aliado à inflação internacional em alta anunciava o fim do auge cíclico. Desta forma, assiste-se ao recrudescimento da inflação, aumento da dívida externa e expansão do hiato de produto em 1975.

Contudo já em 76, com a implantação do II PND, que analisa-se em detalhe a seguir, retornou-se o caminho expansionista. Tal não seria possível se o comportamento dos termos de intercâmbio não fosse excepcionalmente favorável. A recomposição do poder de compra das exportações, assim gerado permitiu um maior alívio no Balanço de Pagamento, conjugada a uma liquidez internacional advinda da reciclagem dos petrodólares permitiu a política anti-cíclica daquele período.

O abandono do II PND, devido a necessidade contenção da inflação e pelo esgotamento da conjuntura excepcional descrita acima, já indicava o caminho da desaceleração das taxas de crescimento do período seguinte $(78 \mathrm{em}$ diante). Simultaneamente, tem-se o aumento da pressão da dívida externa sobre o Balanço de Pagamento, agravada pelo segundo choque do petóleo e pelo choque dos juros. Impôs-se assim, como solução para os dilemas de política econômica, a estratégia centrado no equilíbrio externo em detrimento do equilíbrio interno.

\section{O Comportamento do Balanço de Pagamentos}

A estratégia firmada pelas reformas do período 64/67 buscava um aumento progressivo das exportações brasileiras. Desta forma, seguiu-se uma política de promoção de exportações, visando a substituição das exportações tradicionais. O Quadro 4 ilustra o sucesso desta política.

(6) Esta interpretação deve-se a MALAN, P. \& BONELLI, R. "Os limites do possivel: notas sobre industrialização e balanço de pagamentos nos anos 70". Pesquisa e Planejamento Econômico. 6(2): 353-406, agosto de 1976. 
Por seu turno, as importações tem mostrado uma tendência a rigidificação, principalmente em petróleo, bens intermediários e bens de capital. O Quadro 5 confirma nossa afirmações.

O comportamento do Termos de Intercâmbio, a partir de 78 é tendencialmente declinante. Destaque-se, ainda que este comportamento agravou-se após o segundo choque do petróleo, indicando um possível repasse dos países centrais para seus produtos de exportação como forma de sanearem seus déficits em contra-corrente. 7

Um fato novo, a ser destacado, consiste na deterioração dos Termos de Intercâmbio do Brasil, mesmo quando encontra-se superada a especialização na agricultura de exportação. Isto talvez indique que a deterioração dos Termos de Intercâmbio supera a especificidade dos bens em termos de elașticidade-renda e elasticidade-preço, como em Prebisch, que vislumbrava tal comportamento como forma de apropriação diferenciada de ganhos de produtividade 8 .

A existência de um comportamento perverso nas trocas internacionais indica o caminho recorrentemente buscado pelos países da periferia na superação de suas dificuldades estruturais - a substituição de importações, cuja última etapa analisa-se na seção a seguir.

\subsection{O II PND e a Substituição de Importações}

Anteriormente, teve-se oportunidade de ver que o Brasil conseguiu internalizar plenamente a produção de bens de consumo - sejam eles duráveis ou não-duráveis. Contudo, o caráter desta industrialização, que subsidiaza máquinas e insumos intermediários, bloqueou o desenvolvimento de setores produtores destes bens. Assim, a agricultura cumpria a tarefa do setor de bens de produção ao gerar as divisas necessárias à importação destes bens essenciais ao prosseguimento do processo de acumulação.

Portanto, o requisito fundamental para a completa internalização do circuito da acumulação exige que exista um setor interno produtor de bens de capital capaz de responder ao dinamismo e aos requisitos técnicos dos demais setores, sob pena de submeter o ciclo às flutuações do comércio internacional.

(7) Conforme MUNHOZ, D. "O desequilíbrio externo" , Revista de Economia Política, $1(4): 35-51$, outubro de 1981 .

(8) Estas colocações indicam uma possivel linha de pesquisa, visando esclarecer o sistemá tico comportamento perverso das trocas internacionais para os países da periferia. 
O II PND, ao realizar um diagnóstico semelhante, ${ }^{9}$ procurou romper o estrangulamento na oferta interna de bens de capital e de consumo intermediário, bem como promover mudanças na matriz energética, via Pró-alcool. O esforço concentrado nestes setores levou a uma queda na relação produto-capital que contribuiria para a queda das taxas de crescimento do produto potencial.

Apesar de abandonado prematuramente, os incentivos propiciados pelo II PND elevaram a quase auto-suficiênca interna no fornecimento de bens de capital, conforme Quadro 6.

Todavia a elevada capacidade potencial de suprimento não se tem confirmaḍo por diversas razões, algumas das quais apontadas por José Serra ${ }^{10}$

- facilidade de crédito para importação de sucedâneos;

- menor confiabilidade tecnológica dos bens hacionais;

- necessidade de obtenção de créditos junto ao exterior propiciando a venda "casada" de bens de capital.

A política de busca do equilíbrio externo pela redução do nível de atividade interna tem conseqüências trágicas para o setor de bens de capital 11, parecendo estar colocada em jogo a sobrevivência deste setor internalizado a tão duras penas.

\section{4 - UM MODELO E UMA SIMULAÇĀO PARA O BRASIL}

O objetivo desta seção é realizar uma simulação, através de um modelo econométrico simples, para descrição do comportamento futuro do setor externo da economia brasileira, tendo em vista a manutenção do equilíbrio interno.

\section{1. - Metodologia}

A primeira equação do modelo indica a taxa de crescimento para uma economia aberta, considerando apenas a restrição-poupança:

$$
\ln \frac{Y^{k}}{Y^{k}}=\ln A+\frac{s}{v}+\frac{f}{v}
$$

(9) Conforme COUTINHO, L. "Inflexões e crise da política econômica: 1974-80" Revista de Economia Política, 1(1): 77-100, janeiro de 1981.

(10) SERRA, J. "Ciclo e mudanças estruturais na economia brasileira no após-guerra". Revista de Economia Politica, 2(3): 111-136, julho de 1982.

(11) Como atestam as dificulades financeiras e as recentes quebras de inidústrias do setor. 
onde s é a propensão a poupar, v é a relação incremental capital-produ to f é a entrada de capital por unidade de produ to potencial e A é um parâmetro. Especificando desta forma a taxa de crescimento, admite-se, otimisticamente, que a economia brasileira teria superado a restrição-estrangulamento.

A outra equação do modelo representa a entrada de capitais sobre exportações, $F / X$, em função do hiato do produto, $H$, e do desempenho dos termos de intercâmbio ${ }^{12}$ :

$$
\frac{F}{X}=\alpha+\beta H+\gamma R T
$$

Considenrando: que $f=F / Y^{k}$ pode-se dividir toda a expressão por $Y^{k}$ de forma a permitir a susbtituição de uma equação na outra, possibilitando, escolhidas as trajetórias de $s, v, H$ e RT, determinar os valores para $f$ e $X / Y k$ $=\mathrm{x}$.

As equações estimadas para o Brasil no período 1971/1980 com os "t-scores" entre parênteses, são os seguintes:

$$
\begin{aligned}
& \text { In } \frac{\mathrm{Yk}^{\mathrm{k}}}{\mathrm{Yk}^{\mathrm{k}}}=0,033+0,142 \frac{\mathrm{s}}{\mathrm{v}}+0,297 \frac{\mathrm{f}}{\mathrm{v}} \mathrm{R}^{2}=0,89 \\
& (6,45) \quad(2,71) \\
& F=1,877-2,18 \mathrm{H}-1,33 \mathrm{RT} \quad \mathrm{R}^{2}=0,91 \\
& \mathrm{~F} \quad(12,2) \quad(10,0)
\end{aligned}
$$

A seguir isola se a entrada (ou saída) de capitais por unidade de produ to, $f$, para referendar-se a taxa de crescimento arbitrada.

O passo seguinte consite em obter a evolução das exportações em relação ao produto potencial, sendo conhecidos a entrada percentual de capital, a evolução do hiato do produto e dos termos de intercâmbio. Tomar-se-á uma evolução única para as duas últimas variáveis - no caso do hiato admitir-se-á o pleno-emprego e as relações de troca terão o nével mais alto do período, 130 sendo o ano de 1963 a base igual a 100, de forma a minimizar o esforço da exportação.

(12) Esta especificação da equação provém do desenvolvimento de uma equação semeIhante apresentada por BACHA, E. Os mitos de uma década: ensaios de economia brasileira. Ed. Paz e Terra. 
Considerar-se-á algumas hipósteses sobre a evolução da taxa de crescimento do produto:

- crescimento anual de $3 \%$ que mantém a renda per capita estagnada:

-.. crescimento anual de $7 \%$ que permite a incorporação de parte do contigente de mão-de-obra normalmente desempregada ou sub-empregada, além de absorver os jovens que ingressam anualmente no mercado de trabalho.

Tomou-se em relação à propensão a poupar e à relação incremental capital-produto três referenciais básicos:

- a relação média apresentada no período 1971/80;

- uma relação que considera a elevação das variáveis $\mathrm{s} / \mathrm{v}$ e $\mathrm{v}$ em um desvio-padrão acima da média:

- uma relação que toma as mesmas variáveis diminuídas de um desvio-padrão.

\section{2 - Resultados e interpretação}

O quadro abaixo resume os resultados da simulação:

QUADRO 1 - Simulação de resultados para o Brasil

\begin{tabular}{|c|c|c|c|c|}
\hline & \multicolumn{2}{|c|}{ Hipótese $\underset{Y^{k}}{Y^{k}}=3 \%$} & \multicolumn{2}{|c|}{ Hipótese $\frac{Y^{k}}{Y^{k}}=7 \%$} \\
\hline & $f=F / Y^{k}$ & $x=X / Y^{k}$ & $f=F / Y^{k}$ & $x=X / Y^{k}$ \\
\hline $\begin{array}{l}s / v=10,98 \\
v=4,67\end{array}$ & $-7,7 \%$ & $19 \%$ & $5,5 \%$ & $14 \%$ \\
\hline $\begin{array}{l}s / v=7,81 \\
v=3,41\end{array}$ & $-0,4 \%$ & $1 \%$ & $9,0 \%$ & $22 \%$ \\
\hline $\begin{array}{c}s / v=4,63 \\
v=2,15\end{array}$ & $2,9 \%$ & $7 \%$ & $9,2 \%$ & $23 \%$ \\
\hline
\end{tabular}

Dentre os diversos resultados apresentados pela simulação chama atenção aquele no qual faz-se uma restrição à taxa de crescimento na casa dos $3 \%$, tendo em vista valores altos para s/v e $v$, indicando um forte aumento na propensão a poupar da economia. Este resultado indica a possibilidade de o Brasil tonar-se um exportador líquido de capitais, caso também seja feito um es- 
forço considerável de promoção de exportações. Esta situação é a mais indicada para o pagamento dos débitos do país frente aos credores estrangeiros. Esta possibilidade é de difícil sustentação a longo prazo, pois a história econômica ensina que somente economias amadurecidas podem exportar capitais sem maiores danos a si próprios.

No extremo oposto, a manutenção de uma taxa de crescimento histórico $(7,0 \%)$, superior àquela permitida pela poupança interna, também demanda um grande esforço de exportação, apesar do maciço ingresso de capitais externos, hipóteses bastante irrealista, uma vez que se assite a um fechamento do mercado internacional de crédito às combalidas economias do Terceiro Mundo.

Este exercício mostrou-se bastante relevador das dificuldades a serem enfrentadas pelo Brasil no seu setor externo, mesmo considerando-se que o país tenha superado a restrição-estrangulamento.

Assim, ao que tudo indica, por um largo período de tempo a política de comércio exterior será a pedra-de-toque das políticas econômicas governamentais, supondo-se a manutenção das atuais condições estruturais.

\section{5 - CONCLUSŌES}

O modelo exposto na seção 2 aponta o resultado positivo sobre o crescimento do produto, tanto das exportações, como do aporte de capitais externos. Neste sentido aparece como correta a política de promoção de exportacões. desdie que não corresponde a: uma dedução do consumo interno e de captação de recusos externos ${ }^{13}$.

Contudo, tais políticas podem entrar em choque, caso o endividamen to seja exaustivamente buscado, pois faz-se necessário a elevação da taxa de juros interna, cujos resultados depressivos sobre o nível de ativiadae são sobejamente conhecidos.

Por outro lado, esta mesma política pode levar a imobilização da taxa de câmbio tal como ele é concebida atualmente. Assim, a possibilidade de desvalorizações agressivas do câmbio tende a refrear a tomada de empréstimos externos, enquanto que para os exportadores uma paridade $\mathrm{Cr} \$ /$ US $\$$ em elevação é essencial para seu desempenho, casọ a demanda externa seja

(13) Deve-se levar em conta que os pequenos saldos comerciais obtidos até 1982 são mais resultado da contentação de importações do que produto de um crescimento excepcional das exportações. 
elástica. Desta forma, seria desejável uma desvinculação da taxa de câmbio financeira da taxa comercial

$O$ coeficiente $m_{i}$ - dependência em relação a bens intermediários tem, por sua vez, um caráter depressivo sobre a economia. Viu-se anterior. mente que o esforço de substituição de importações do II PND alcançou suas metas tanto na área de bens intermediários como na área energética.

$\mathrm{Na}$ área de bens de capital viu-se, na seção 3, que a capacidade de atendiamento da demanda pela produção nacional é bastante elevada, além disso, a margem de capacidade ociosa do setor é considerável. Assim, a retomada deste setor depende da reversão das políticas pró-cíclicas atualmente em voga. Finalmente, cabe lembrar que o aumento da utilização do parque produtivo ocioso gera poupança e aumenta o consumo, pela via do aumento do emprego.

O aprofundamento da substituição de importações como o caminho para a retomada da expansão pode trazer efeitos perversos sobre a economia, caso o aparelho de intermediação financeira não esteja apto a executar o financiamento de projetos de longo prazo, pela piora da distribuição de renda, através da elevação dos patamares de inflação.

A viabilização desta estratégia de crescimento requer um aprofunda. mento da ação estatal na programação econômica. Porém, para que isso se torne possível faz-se necessário um reordenamento da capacidade fiscal ${ }^{14}$ com melhor repartiç̧ão da carga tributária, acentuando sua progressividade, além da recuperação do instrumento da dívida pública. Outras medidas a serem tomadas dizem respeito ao reordenamento do setor financeiro que foi bastante competente para o setor de bens de consumo durável, mas que na crise do modo de acumulação tende a ganhar autonomia em relação ao setor produtivo.

Uma alternativa dentro do atual quadro de restrição de divisas; como forma de adquirir graus de liberdade, seria o incremento do comércio inter-

(14) Uma alternativa fiscal para incentivo do setor produtor de bens de capital e intermediários seria a utilização do conceito de proteção efetiva, que leva em conta a proteção tarifária distribuída ao longo do processo produtivo. Na fase de substituição de importações de bens' de consumo, estes recebiam uma elevada proteção, enquanto que os bens intermediários e de capital recebiam proteção negativa, ou seja, eram subsidiados. Desta forma, o preço do capital era barateado em relação a dotação de fatores, favorecendo-se sua importação. Agora, pleiteia-se a reversão desta estrutura de preços relativos através da proteção efetiva para os insumos do processo produtivo. Ver a respeito MALAN, P. \& BERGSTEN, J. "A estrutura de produção industrial no Brasil." Revista Brasileira de Economia 24(3): $97-190$, junho de 1970. 
nacional entre os países da periferia como forma de economizar dólares. Neste sentido, poderiam ser implementadas iniciativas como Câmaras de Compensação. Evidentemente, nesta nova forma de interação cabe um papel privilegiado ao Brasil que detém o maior parque industrial do III Mundo e que possui um grande grau de complementaridade com as demais economias semi-indu strializadas.

Partindo por vertentes mais otimistas de raciocínio, admitindo-se o rompimento do estrangulamento externo, seja por um reordenamento finan. ceiro internacional ou por um aprofundamento do esquema de divisão internacional do trabalho com a retomada do comércio internacional, pode-se esperar um novo ciclo expansivo para a economia brasileira. As condições para esta arrancada, que certamente dar-se-á nụm patamar mais al to que a recuperação da década de 30 e do que o "milagre", estão dadas pela margens de capacidade ociosa e pelo maior grau de complementaridade inter-industrial, indicando um menor número de dificuldades estru turais a serem rompidas.

Desta forma, na ausência de um reordenamento profundo na economia brasileira capitaneado pelo Estado, continuar-se-á na dependência de fatores exógenos, cujo prognóstico, para dizer-se o mínimo é bastante problemático.

(Originais recebidos em setembro de 1983, revistos em julho de 1984)

\section{BIBLIOGRAFIA}

01. BACHA, E. “Balanço de Pagamentos, inflação e crescimento uma reinterpretação do modelo de dois hiatos" in ANPEC. Anais de IX Encontro, vol. 6 , novembro de 1981.

$02 . \quad$ "Crescimento com oferta ilimitada de divisas: uma reavaliação do modelo de dois hiatos". Pesquisa e Planejamento Econômico, 12(2): 285-310, agosto de 1982.

03. Introdução à macroeconomia : uma perspectiva brasileira. Ed. Campus, Rio de Janeiro, 1980.

04. BALASSA, B. “Os países de industrialização recente e a crise do petróleo. Pesquisa e Planejamento Econômico. 11(1): 1-77, janeiro de 1981.

05. PREBISCH, R. "O desenvolvimento econômico da América Latina e alguns dos seus principais problemas". Revista Brasileira de Economia, 3(3): 47-111, setembro de 1949.

06. TAYLOR, L. \& CARDOSO, E. "Crescimento, distribuição de renda e Balanço de Pagamentos". Pesquisa e Planejamento Econômico 6(2): 290351, agosto de 1976. 


\section{ANEXOS}

QUADRO No 1 - Produto Potencial, Efetivo e Hiato do Produto para o Brasil (19601980) Produto Efetivo de $1970 \Leftrightarrow 100$.

\begin{tabular}{cccc}
\hline ANOS & $\begin{array}{c}\text { PRODUTO POTENCIAL } \\
(1)\end{array}$ & $\begin{array}{c}\text { PRODUTO EFETIVO } \\
(2)\end{array}$ & $\begin{array}{c}\text { HIATO DO PRODUTO } \\
(1)-(2) /(1)\end{array}$ \\
\hline 1960 & 56,2 & 54,6 & 0,029 \\
1961 & 60,4 & 60,4 & 0 \\
1962 & 65,0 & 63,8 & 0,019 \\
1963 & 70,1 & 65,0 & 0,078 \\
1964 & 75,5 & 67,1 & 0,125 \\
1965 & 81,3 & 69,1 & 0,177 \\
1966 & 87,6 & 71,7 & 0,222 \\
1967 & 94,3 & 75,2 & 0,254 \\
1968 & 101,5 & 83,6 & 0,214 \\
1969 & 109,4 & 91,9 & 0,190 \\
1970 & 117,8 & 100 & 0,178 \\
1971 & 126,8 & 113,3 & 0,119 \\
1972 & 136,6 & 126,6 & 0,079 \\
1973 & 147,1 & 144,2 & 0,020 \\
1974 & 158,3 & 158,3 & 0 \\
1975 & 170,6 & 167,3 & 0,020 \\
1976 & 183,7 & 182,7 & 0,005 \\
1977 & 197,9 & 191,3 & 0,035 \\
1978 & 212,4 & 207,7 & 0,045 \\
1979 & 228,1 & 215,7 & 0,054 \\
1980 & 245,0 & 233 & 0,049 \\
\hline
\end{tabular}

Fonte: BACHA, E. Introdução à macróeconomia: uma perspectiva brasileira. Ed. Campus. p. 56

Quadro n? 2 - Desempenho do setor externo - $1960-80$

US $\$ 1.000,00$ US $\$ 1.000,00$

\begin{tabular}{ccccc}
\hline ANOS & $\begin{array}{c}1963=100 \\
\text { RELAÇOES DE } \\
\text { TROCA }\end{array}$ & $\begin{array}{c}\text { SALDO EM (1) } \\
\text { CONTA COR. } \\
\text { RENTE }\end{array}$ & EXPORTAÇÕES (2) & $(1) /(2)$ \\
\hline 1960 & 116 & -509 & 1269 & $-0,4011$ \\
1961 & 113 & -388 & 1403 & $-0,2053$
\end{tabular}




\begin{tabular}{rrrrr}
1962 & 100 & -414 & 1214 & $-0,3410$ \\
1963 & 100 & -147 & 1406 & $-0,1046$ \\
1964 & 115 & 102 & 1430 & $+0,0713$ \\
1965 & 108 & 283 & 1595 & $+0,1774$ \\
1966 & 101 & -33 & 1741 & $-0,0190$ \\
1967 & 97 & -264 & 1654 & $-0,1596$ \\
1968 & 99 & -503 & 1881 & $-0,2674$ \\
1969 & 105 & -154 & 2311 & $-0,0666$ \\
1970 & 115 & -583 & 2739 & $-0,2129$ \\
1971 & 105 & -1321 & 2904 & $-0,4547$ \\
1972 & 114 & -1489 & 3991 & $-0,3731$ \\
1973 & 124 & -1688 & 6199 & $-0,2723$ \\
1974 & 102 & -7122 & 7951 & $-0,8957$ \\
1975 & 98 & -6700 & 8670 & $-0,7728$ \\
1976 & 110 & -5977 & 10128 & $-0,5901$ \\
1977 & 130 & -4037 & 12120 & $-0,3331$ \\
1978 & 112 & -7061 & 12659 & $-0,5578$ \\
1979 & 101 & -10495 & 15244 & $-0,6885$ \\
1980 & 84 & -12807 & 21032 & $-0,6362$ \\
\hline
\end{tabular}

Fontes: Anuário Estatístico do Brasil e Conjuntura Econômica - vários números. SERRA, J. Ciclio e mudanças Estruturais na Economia brasileira no apósguerra. Revista de Economia Política, 2(2): 5-45, março de 1982.

Quadro nㅇ 3 - Coeficientes de Importação da Indústria de Transformação, de 1965 a 1981, Cr $\$ 10$ com base em 1970 e Percentagens

\begin{tabular}{rcccccrr}
\hline ANO & $\begin{array}{c}\text { Produção } \\
\text { Industrial } \\
(1)\end{array}$ & $\begin{array}{c}\text { Exportação } \\
\text { Industrial } \\
(2)\end{array}$ & $\begin{array}{c}\text { Importação } \\
\text { Industrial } \\
(3)\end{array}$ & $\begin{array}{c}(2) \\
(1) \\
(\%)\end{array}$ & $\begin{array}{c}(3) \\
(1)+(3)-(2) \\
(\%)\end{array}$ & $\begin{array}{r}(1)+(3) \\
(\%)\end{array}$ & $\begin{array}{r}(3) \\
(1) \\
(\%)\end{array}$ \\
\hline 1965 & 57.366 & 1.105 & 4.130 & 1,9 & 6,8 & 6,7 & 7,2 \\
1966 & 65.456 & 986 & 5.721 & 1,5 & 8,2 & 8,0 & 8,7 \\
1967 & 65.552 & 1.303 & 6.480 & 2,0 & 9,2 & 9,0 & 9,9 \\
1968 & 76.630 & 1.363 & 8.819 & 1,8 & 10,5 & 10,3 & 11,5 \\
1969 & 84.600 & 1.774 & 9.424 & 2,1 & 10,2 & 10,0 & 11,1 \\
1970 & 95.513 & 2.459 & 11,869 & 2,6 & 11,3 & 11,1 & 12,4 \\
1971 & 106.879 & 2.790 & 15.631 & 2,6 & 13,1 & 12,8 & 14,6 \\
1972 & 121.779 & 3.887 & 19.109 & 3,2 & 13,9 & 13,6 & 17,7 \\
1973 & 141.932 & 4.023 & 22.812 & 2,8 & 14,2 & 13,8 & 16,1 \\
1974 & 153.012 & 4.046 & 32.304 & 2,6 & 17,8 & 17,4 & 21,1
\end{tabular}




\begin{tabular}{llllllll}
1975 & 158.838 & 4.484 & 28.822 & 2,8 & 15,7 & 15,4 & 18,1 \\
1976 & 179.374 & 4.658 & 25.594 & 2,6 & 12,8 & 12,5 & 14,3 \\
1977 & 184.627 & 5.768 & 22.730 & 3,1 & 11,3 & 11,0 & 12,3 \\
1978 & 197.808 & 7.406 & 24.078 & 3,7 & 11,2 & 10,8 & 12,2 \\
1979 & 210.988 & 8.340 & 26.213 & 4,0 & 11,5 & 11,1 & 12,4 \\
1980 & 227.035 & 10.206 & 28.377 & 4,5 & 11,6 & 11,1 & 12,5 \\
1981 & 213.186 & 11.672 & 26.287 & 5,5 & 11,5 & 11,0 & 12,3 \\
\hline
\end{tabular}

Fonte: SERRA, J. Op. cit. 122

Quadro n? 4 -- Composição da Pauta de Exportações Brasileiras de Mercadorias (US\$ mi|hões), 1971 e 1980

\begin{tabular}{lcc}
\hline DISCRIMINAÇÃO & 1971 & 1980 \\
\hline Café (em grão e solúvel) & $823(28 \%)$ & $2773(14 \%)$ \\
Outros Produtos Primários & & \\
(açúcar cristal e refinado inclusive) & $1255(42 \%)$ & $6640(33 \%)$ \\
Semimanufaturados & $241(9 \%)$ & $2025(10 \%)$ \\
Manufaturados & $617(21 \%)$ & $8694(43 \%)$ \\
Total & 2904 & 20132 \\
\hline
\end{tabular}

FONTE: Boletim Mensal, Banco Central do Brasil.

Quadro n? 5 - Composição da Pauta de Importações Brasileiras.

(US $\$$ milhões), 1971 è 1980

\begin{tabular}{lcc}
\hline DISCRIMINAÇÃO & 1971 & 1980 \\
\hline Bens de Consumo & $472(15 \%)$ & $2351(10 \%)$ \\
Combustíveis e Lubrificantes & $377(12 \%)$ & $10210(45 \%)$ \\
Matérias-Primase Bens & & \\
Intermediários & $1160(35 \%)$ & $6008(26 \%)$ \\
Bens de Capitais & $1239(38 \%)$ & $4392(19 \%)$ \\
Total & 3247 & 22961 \\
\hline
\end{tabular}

FONTE: Boletim Mensal, Banco Central do Brasil. 
Quadro n? 6 - Capacidade Potencial e Efetiva no Fornecimento de Equipamentos (\%) Média dos Anos 1979, 1980 e 1981

\begin{tabular}{lcc}
\hline DISCRIMINAÇÃO & POTENCIAL & EFETIVA \\
\hline Energia Elétrica & 85 & 80 \\
Siderurgia & 85 & 75 \\
Petróleo & 90 & 80 \\
Petroquímica e Química & 75 & 70 \\
Celulose e Papel & 90 & 75 \\
Cimento & 95 & 95 \\
Mineração & 75 & 70 \\
Ferroviário & 95 & 70 \\
Naval & 90 & 85 \\
\hline
\end{tabular}

FONTE: ADIB, Citado por SERRA, José. Op. Cit., p. 136. 